\title{
Viabilidade técnica e econômica do aproveitamento das águas de chuva e cinza para consumo não potável em edifício residencial de Santa Maria (RS)
}

\author{
Technical and economic feasibility of the use of rainwater \\ and greywater for non-potable consumption in a residential \\ building in Santa Maria (RS) \\ Data de entrada: \\ 13/04/2016 \\ - Data de aprovação: \\ 20/07/2016
}

Vinicius Kuchinski / Maria do Carmo Cauduro Gastaldini

DOI: $10.4322 /$ dae.2016.031

\section{Resumo}

A preocupação com a falta de água subsidia o crescimento de ideias sustentáveis e que demandam menos recursos hídricos. Por isso, avaliou-se a viabilidade técnica e econômica de um projeto de aproveitamento de águas de chuva e cinza para o consumo não potável em edifício residencial. 0 edifício, localizado na cidade de Santa Maria (RS), conta com 42 apartamentos com padrão médio de acabamento e área privativa média de $92 \mathrm{~m}^{2}$. Para tal, utilizou-se o método da simulação para o aproveitamento da água de chuva e, para o sistema de aproveitamento de água cinza, consideraram-se metodologias e sistemas propostos na literatura recente. Com relação à viabilidade econômica, foi empregado o método do VPL. O reservatório foi dimensionado em $15 \mathrm{~m}^{3}$ e, com o sistema de aproveitamento da água cinza, conseguiu atender a 100\% da demanda de água não potável. O sistema, incluindo a estação de tratamento de água cinza, teve um custo de $\mathrm{R} \$ 48.139,77$ e gerou economia de água potável de $\mathrm{R} \$$ 15.346,50/ano, tornando-se técnica e economicamente viável. Palavras-chave: Aproveitamento de água cinza. Aproveitamento de água de chuva. Sustentabilidade.

\section{Abstract}

The concern about the lack of water subsidizes the growing of sustainable ideas that demand less water resources. Therefore, it was aimed to assess the technical and economic feasibility of the rainwater use and greywater reuse for non-potable consumption in a residential building. The building is located in the city of Santa Maria (RS) and has 42 apartments with an average standard of finishing and private average area of $92 \mathrm{~m}^{2}$. For this purpose, it was used the simulation method to the use of rainwater, besides methods and systems proposed in recent literature for greywater system. About the economic viability, it was used the NPV method. The reservoir was sized at $15 \mathrm{~m}^{3}$ and, with greywater use system, ensures $100 \%$ of non-potable water demand. Including the greywater treatment plant, the full system implementation cost was $R \$ 48,139.77$, and the system generated an annual saving in drinking water of $R \$ 13,262.94$, showing up technically and economically viable. Keywords: greywater reuse, rainwater use, sustainability

Vinícius Kuchinksi - Engenheiro Civil pela Universidade Federal de Santa Maria (UFSM). Mestre em Engenharia Civil pela UFSM. Engenheiro Civil do Governo do Estado do Rio Grande do Sul. Departamento de Administração do Patrimônio do Estado, Secretaria da Modernização Administrativa e dos Recursos Humanos - Governo do Estado do Rio grande do Sul.

Maria do Carmo Cauduro Gastaldini - Professora Titular do Departamento de Engenharia Sanitária e Ambiental, do Programa de Pós-Graduação em Engenharia Civil e do Programa de Pós-Graduação em Engenharia Ambiental da Universidade Federal de Santa Maria.

Endereço para correspondência("): Departamento de Engenharia Sanitária e Ambiental - Av. Roraima 1000, Prédio 10 - Laboratórios do Centro de Tecnologia (CTLAB), Campus Universitário - Bairro Camobi, CEP 97105-900 - Santa Maria/RS. 


\section{INTRODUÇÃO}

O desenvolvimento sustentável surgiu, entre outros motivos, com a preocupação com a forma como os recursos naturais são consumidos, visto que são retirados e explorados até sua total exaustão ou sua completa extinção. Nesse âmbito, é possível inferir que isso ocorre em razão de geralmente não existir um plano de recuperação ambiental das áreas e dos recursos explorados.

A situação agrava-se, principalmente, quando o recurso é a água, que é indispensável para a manutenção da vida no planeta Terra. Com essa escassez, é imprescindível que o homem procure formas alternativas de consumir os recursos, de maneira racional e sustentável. Nesse cenário, uma solução sustentável seria tratar e reusar, para fins benéficos, os esgotos já disponíveis nas áreas urbanas, para complementar o abastecimento público. Essa prática contribuiria substancialmente para o aumento da robustez dos sistemas e tornaria o conceito de resiliência pouco significativo, uma vez que eliminaria as condições de estresse associadas à redução da disponibilidade hídrica em mananciais utilizados para abastecimento público (HESPANHOL, 2015).

Primeiramente, é fundamental a conscientização da população sobre o uso racional da água e a necessidade de implantação de um sistema de abastecimento de água seletivo. Ainda, uma vez que, na maioria das edificações, a água potável é utilizada para a realização de todas as atividades (SALLA et al., 2013), o aproveitamento das águas de chuva e cinza proporcionaria o suprimento da demanda de água não potável, poupando-se a utilização de uma água de boa qualidade, que passou por diversos processos para chegar à potabilidade, contribuindo com o meio ambiente e a sustentabilidade. $\mathrm{O}$ aproveitamento da água de chuva contribui, também, com a diminuição do pico de escoamento superficial após as chuvas, que, devido ao processo de urbanização das bacias hidrográficas, é aumentado.
Contudo, para a utilização dessas águas (cinza e de chuva), deve ser feito um estudo de viabilidade técnica, para avaliar sua disponibilidade e analisar, de acordo com sua finalidade, a necessidade de tratamento prévio. De fato, o sistema de aproveitamento de águas pluvial e cinza depende, basicamente, do destino final e do tratamento necessário para a água, de modo que não traga riscos à saúde, tubulações, pisos, carros, plantas etc.

\section{OBJETIVO}

Este estudo teve como objetivo avaliar a viabilidade técnica e econômica de um sistema de aproveitamento das águas de chuva e cinza para fins não potáveis em edifício residencial da cidade de Santa Maria (RS).

\section{FUNDAMENTAÇÃO TEÓRICA}

\subsection{Estudo da viabilidade técnica}

\section{Sistema de aproveitamento da água de chuva}

Até mesmo no Brasil, país com grande oferta de água doce, os sinais de escassez começam a aparecer nas regiões Nordeste e Norte, onde menos de $18 \%$ e $14 \%$ da população urbana é atendida por sistemas de abastecimento satisfatórios, respectivamente (LOURENÇO, 2013).

Apesar de o sistema de coleta e aproveitamento da água de chuva ser utilizado há anos em algumas regiões do país, são recentes os avanços na legislação e normas técnicas a respeito do uso dessa água para fins não potáveis. Um exemplo de legislação relacionada ao consumo racional da água é a Lei Municipal n 10.785, de Curitiba (PR), que passou a viger em 2003. A lei curitibana aborda o Programa de Conservação e Uso Racional da Água nas Edificações (PURAE), que tem como objetivo instituir medidas que induzam à conservação, ao uso racional e à utilização de fontes alternativas, como a água proveniente de chuvas e as águas servidas (água cinza, por exemplo). 
A água de chuva, para ser utilizada, deve passar por um controle de qualidade, que, de acordo com sua finalidade, deve atender a padrões previamente estabelecidos pelos órgãos responsáveis. As diretrizes para o acompanhamento da qualidade da água são dadas pelas Resoluções CONAMA $n^{\circ} 274 / 2000$ e n 357/2005, pela Portaria MS n 2.914/2011 e pela NBR 15527 (ABNT, 2007).

O sistema de aproveitamento de água pluvial depende, basicamente, do destino final e do tratamento necessário para a água, podendo seu fluxograma ser visualizado na Figura 1. As instalações devem obedecer, obrigatoriamente, às instruções contidas nas normas: NBR 10844 (ABNT, 1989), para as calhas e condutores horizontais e verticais; NBR 12213 (ABNT, 1992), para as grades de remoção de detritos; NBR 15527 (ABNT, 2007), que dispõe sobre a utilização da água de chuva para fins não potáveis e seus requisitos; NBR 12217 (ABNT, 1994), para o projeto de reservação; NBR 12214 (ABNT, 1992), para o sistema de bombeamento de água; e NBR 5626 (ABNT, 1998), que aborda as instalações prediais de água fria.

É destacável a observação de alguns pontos importantes que estão presentes nas normas, como, por exemplo, o impedimento da retrossifonagem, a prevenção de refluxo e a proteção contra conexão cruzada, de forma que as fontes de água potável não entrem em contato com as fontes de água não potável. Além disso, fazem-se necessários dispositivos de segurança para os reservatórios, como extravasor, esgotamento, cobertura, entre outros.

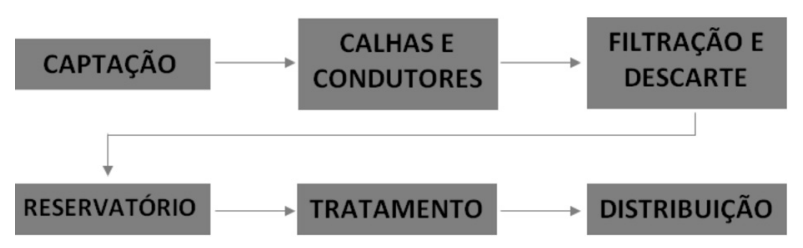

Figura 1 -Fluxograma de aproveitamento da água de chuva.
Ainda segundo a NBR 15527 (ABNT, 2007), o volume de água de chuva aproveitável depende da área de coleta, da precipitação, do coeficiente de escoamento superficial e da eficiência do sistema de captação. Assim, o coeficiente de escoamento superficial, também chamado coeficiente de runoff ou coeficiente $C$, é um adimensional resultante da relação entre o volume de água que escoa sobre uma superfície e o volume de água precipitado sobre ela. Além disso, a norma sugere o descarte dos primeiros $2 \mathrm{~mm}$ de chuva, para que a sujeira disposta sobre a área de drenagem não entre no sistema de captação, sendo, assim, rejeitada por dispositivo especial. Esse descarte foi confirmado por Hagemann (2009) para a região de Santa Maria (RS).

A mesma norma faz menção ao cálculo do volume dos reservatórios, que deve ser dimensionado com base em critérios técnicos, econômicos e ambientais, levando em conta as boas práticas da engenharia, podendo, a critério do projetista, ser utilizado um dos métodos contidos no Anexo A da norma ou outro, desde que seja devidamente justificado.

\section{Sistema de aproveitamento de água cinza}

Conforme a Agência Nacional de Águas (ANA, 2005), a água cinza é um efluente que não possui contribuição da bacia sanitária, ou seja, corresponde ao efluente gerado pelo uso de banheiras, chuveiros, lavatórios, máquinas de lavar roupas e pias de cozinha (estas com ressalva, pois diversos autores não consideram seu efluente água cinza pela presença de óleos, graxas e restos de alimentos).

Sua utilização deve ser feita de maneira a contribuir para o desenvolvimento sustentável e a conservação dos recursos, sem prejuízo à saúde pública ou ao meio ambiente (MADUNGWE; SAKURIGWA, 2007). Em grande parte do mundo, o reúso de esgotos ocorre sem problemas, tanto que a Organização das Nações Unidas (ONU) mantêm um programa global de reúso planejado da água, com o objetivo de garantir o uso sustentado, além 
da conservação e integridade dos ecossistemas (SAMPAIO, 2006).

As tecnologias aplicadas para o tratamento de água cinza incluem sistemas físicos, químicos e biológicos, sendo a maior parte precedida pelo passo de separação do sólido e líquido, como prétratamento, seguida de desinfecção, como póstratamento (Ll et al., 2009).

A prática do aproveitamento de água cinza significa o engajamento na redução do consumo de água potável e constitui um uso racional da água, resultando em preservação ambiental. Como exemplo, um esquema de instalação hidrossanitária de aproveitamento de água cinza está representado na Figura 2, mostrando os detalhes e itens que se fazem necessários para a correta disposição do sistema, incluindo o sistema de tratamento, composto, principalmente, pela Estação de Tratamento de Água Cinza (ETAC).

Segundo Jeppesen (1997), as orientações para o aproveitamento doméstico de água cinza são: proteger as pessoas de doenças transmitidas pela água devido à operação de instalações de reutilização; assegurar que as instalações não causem nenhum dano ambiental para a vizinhança; e aplicar a água cinza em um sistema que resulte numa boa relação custo-benefício. Al-Jayyousi (2003), por sua vez, após testes de reutilização de água cinza na Jordânia, afirmou que a qualidade da água tem grande variação conforme o sistema de tratamento utilizado, sendo necessária a utilização de um sistema que atenda às necessidades dos usuários.

\section{Demanda de água não potável}

Existe uma dificuldade muito grande em prever a demanda de água não potável, pois é impossível mensurar a quantidade de água que cada pessoa consome para realizar a mesma atividade - enquanto alguém pode utilizar $100 \mathrm{~L}$ de água por dia, outra pessoa pode consumir $250 \mathrm{~L}$, por exemplo.

Os usos da água em uma residência podem ser internos e externos e sua quantificação é, geralmente, feita por estimativa de demanda, visto que as pesquisas no Brasil com relação ao consumo residencial de água são escassas (TOMAZ, 2003).

Para ter uma estimativa de demanda, Tomaz (2007) apresentou tabelas que relacionam atividades que consomem água com a quantidade de água necessária para sua realização. A Tabela 1 exibe as estimativas de demanda para os usos internos, enquanto a Tabela 2 expõe as estimativas para usos externos.

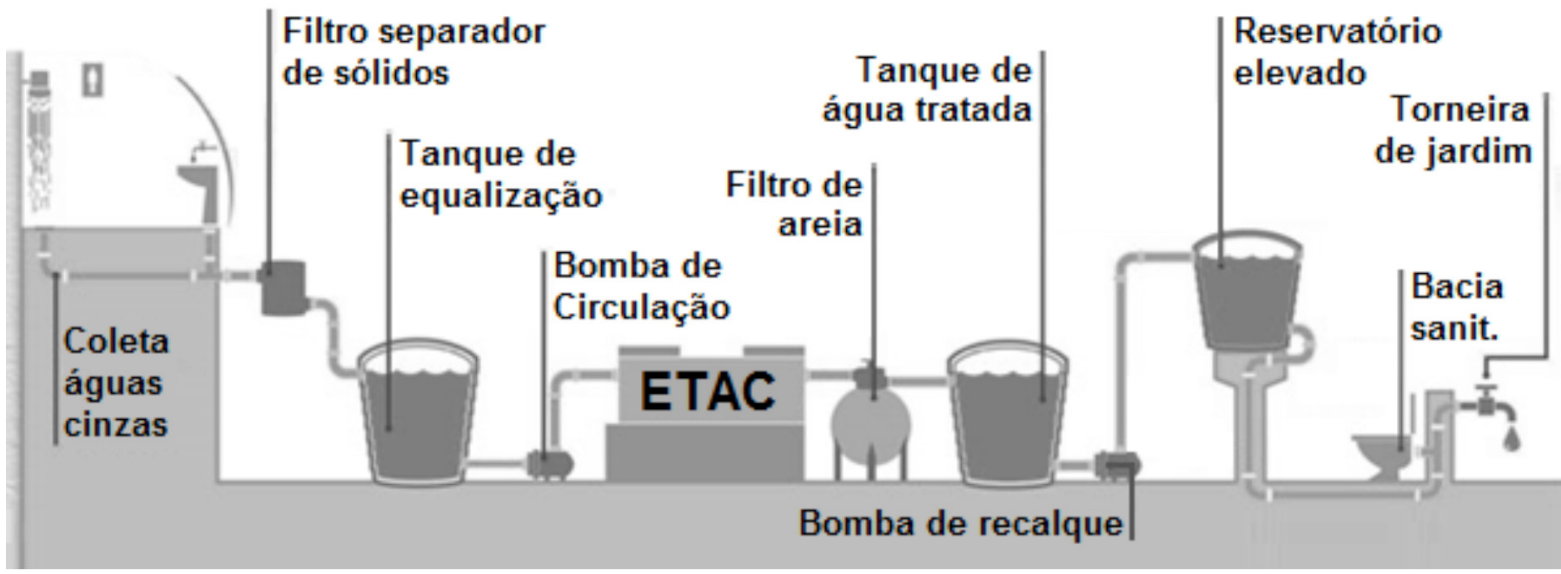

Figura 2 - Esquema do sistema de aproveitamento de água cinza. Fonte: Adaptado de Ecoracional (2014). 
Tabela 1 - Estimativa de demanda de água não potável para usos internos.

\begin{tabular}{|l|l|c|c|c|}
\hline \multirow{2}{*}{ Uso interno } & \multicolumn{1}{|c|}{ Unidade } & \multicolumn{3}{c|}{ Parâmetro } \\
\cline { 3 - 5 } $\begin{array}{l}\text { Bacia sanitária } \\
\text { - volume de } \\
\text { descarga }\end{array}$ & $\begin{array}{l}\text { Litros/ } \\
\text { descarga }\end{array}$ & 6,8 & 18 & 9 \\
\hline $\begin{array}{l}\text { Bacia sanitária } \\
\text { - frequência } \\
\text { de uso }\end{array}$ & $\begin{array}{l}\text { Descarga/ } \\
\text { pessoa.dia }\end{array}$ & 4 & 6 & 5 \\
\hline $\begin{array}{l}\text { Vazamento de } \\
\text { bacia sanitária }\end{array}$ & Percentagem & 0 & 30 & 9 \\
\hline $\begin{array}{l}\text { Máquina de } \\
\text { lavar roupas } \\
\text { - volume de } \\
\text { água }\end{array}$ & Litros/ciclo & 108 & 189 & 108 \\
\hline $\begin{array}{l}\text { Máquina de } \\
\text { lavar roupas }\end{array}$ & $\begin{array}{l}\text { Carga/pessoa. } \\
\text { dia }\end{array}$ & 0,2 & 0,37 & 0,37 \\
\hline
\end{tabular}

Fonte: Adaptado de Tomaz (2007).

Tabela 2 - Estimativa de demanda de água não potável para usos externos.

\begin{tabular}{|l|l|c|}
\multicolumn{1}{|c|}{ Uso externo } & \multicolumn{1}{|c|}{ Unidade } & Valor \\
\hline $\begin{array}{l}\text { Rega de gramado ou } \\
\text { jardins }\end{array}$ & Litro/dia.m² & 2 \\
\hline $\begin{array}{l}\text { Lavagem de carros - } \\
\text { volume de água }\end{array}$ & Litros/lavagem.carro & 150 \\
\hline $\begin{array}{l}\text { Lavagem de carros - } \\
\text { frequência }\end{array}$ & Lavagem/mês & 4 \\
\hline
\end{tabular}

Fonte: Adaptado de Tomaz (2007).

\section{Estudo da viabilidade econômica}

Segundo Kraychete (1997), o estudo da viabilidade engloba dois aspectos relacionados com as questões estritamente econômicas. 0 primeiro é o conjunto de perguntas que devem ser feitas para a implantação da atividade que se quer desenvolver, enquanto o segundo aborda as contas necessárias, ou seja, basicamente, a análise dos custos (variáveis e fixos) para a instalação do projeto, da depreciação e da receita gerada. Algumas das perguntas relacionadas à primeira parte do estudo da viabilidade econômica incluem o processo de produção, os investimentos, o consumo de energia, a comercialização (no caso de uma empresa que está vendendo um produto), os impostos e a legislação.

Nesse contexto, o Valor Presente Líquido (VPL) é um indicador que facilita a escolha do sistema em relação à sua viabilidade econômica, uma vez que define as movimentações futuras de um projeto em um único valor no presente.

Com base nisso, Fernandes et al. (2007) estudaram a viabilidade econômica de instalações de sistemas de aproveitamento de água de chuva por cisternas na Universidade Federal do Rio Grande do Norte. O método de estudo utilizado pelos pesquisadores foi o cálculo do VPL, concluindo-se que o sistema de aproveitamento de água pluvial mostra-se economicamente viável frente à utilização da água do sistema de abastecimento público da cidade.

\section{METODOLOGIA \\ 4.1 Área de estudo}

O trabalho foi baseado na criação de um projeto de aproveitamento de água cinza e aplicação da água de chuva para consumo não potável em um edifício residencial. 0 edifício chama-se Residencial Gabro e está sendo executado em Santa Maria (RS) (Figura 3), localizado na Rua Visconde de Pelotas, 2220.

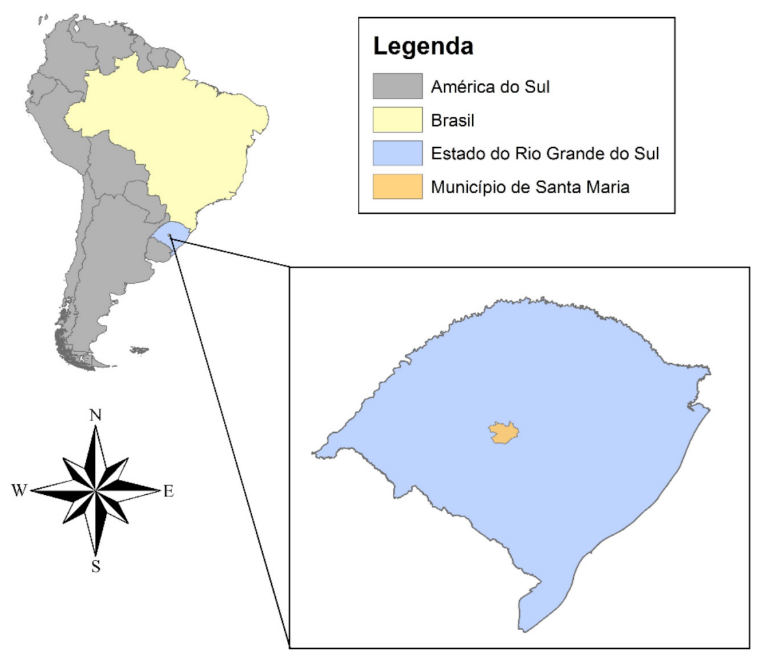

Figura 3 - Localização da área de estudo - Residencial Gabro. 
O edifício, que tem padrão de acabamento médio, conta com três pavimentos de garagem, oito pavimentos tipo e cobertura. O pavimento tipo possui dois apartamentos com três dormitórios $\left(125 \mathrm{~m}^{2}\right.$ de área privativa) e três apartamentos com dois dormitórios (dois com $75 \mathrm{~m}^{2}$ de área privativa e um com $60 \mathrm{~m}^{2}$ ). A cobertura possui dois apartamentos com quatro dormitórios $\left(230 \mathrm{~m}^{2}\right.$ de área privativa), assim totalizando 42 apartamentos.

\subsection{Viabilidade técnica}

O projeto teve como foco a utilização da água de chuva e o aproveitamento da água cinza para fins não potáveis, começando pelas unidades habitacionais, as quais abastecem as bacias sanitárias. Nas áreas úteis, o abastecimento dessas águas dá-se em pontos de lavagem do condomínio e rega de jardins ou gramados.

\section{Oferta pluviométrica de Santa Maria}

Para análise da oferta pluviométrica de Santa Maria, foram utilizados os dados de precipitação referentes à estação pluviométrica do $8^{\circ}$ Distrito de Meteorologia ( $8^{\circ}$ DISME) do Ministério da Agricultura, distante aproximadamente $12 \mathrm{~km}$ da área de estudo, no período de $1^{\circ}$ de janeiro de 1990 a $1^{\circ}$ de janeiro de 2010.

\section{Quantificação da demanda de água não potável}

A quantidade de pessoas que residirão no edifício foi calculada a partir da Tabela 3, indicando a estimativa de água consumida por apartamento, de acordo com o número de dormitórios. Além da informação fornecida pela Tabela 3, utilizaram-se dados publicados pela Companhia de Saneamento Básico do Estado de São Paulo (SABESP, 2012, p. 15), que recomendam, para fins de projeto, utilizar o consumo per capita em residências de $150 \mathrm{~L}$.
Tabela 3 - Estimativa de consumo de água por dormitório em residência.

\begin{tabular}{|c|c|}
\hline Quantidade de quartos & Consumo (L/dia) \\
\hline 1 & 400 \\
\hline 2 & 600 \\
\hline 3 & 800 \\
\hline 4 ou mais & 1.000 \\
\hline
\end{tabular}

Fonte: Curitiba (2006).

A partir das informações das Tabelas 1 e 2, algumas considerações de projeto foram feitas para o desenvolvimento do trabalho:

- Bacia sanitária: cada pessoa utiliza a descarga da bacia sanitária cinco vezes ao dia; cada descarga tem volume de $9 \mathrm{~L}$ de água.

- Área de jardim: o total da área de jardins do edifício é de aproximadamente $140 \mathrm{~m}^{2}$, sendo regado por $2 \mathrm{~L} / \mathrm{m}^{2}$.dia, quatro dias por mês.

- Área de limpeza: considerou-se que a limpeza geral é feita uma vez por semana e, para cada limpeza, são gastos $300 \mathrm{~L}$ de água.

\section{Dimensionamento do reservatório de águas de} chuva e cinza

A NBR 15527 (ABNT, 2007) traz, em seus anexos, métodos de dimensionamento do reservatório de água de chuva, cada um com suas peculiaridades. O método escolhido foi o da simulação (Equação 1), que se baseia na determinação do percentual de consumo que será atendido em função de um tamanho de reservatório previamente definido. Também é chamado método de análise de simulação de um reservatório com capacidade suposta (RUPP et al., 2011).

$S_{(t)}=Q_{(t)}+S_{(t-1)}-D_{(t)}$

Sendo: $0<S_{(t)}<V$ e $Q_{(t)}=C \cdot P(t) \cdot A$

Em que:

$\mathrm{S}_{(\mathrm{t})}=$ volume de água no reservatório no tempo $\mathrm{t}\left(\mathrm{m}^{3}\right)$. 
$\mathrm{S}_{(\mathrm{t}-1)}=$ volume de água no reservatório no tempo $\mathrm{t}-1\left(\mathrm{~m}^{3}\right)$.

$\mathrm{Q}_{(\mathrm{t})}=$ volume de água de chuva aproveitável no tempo $\mathrm{t}\left(\mathrm{m}^{3}\right)$.

$D_{(t)}=$ demanda ou consumo no tempo $t\left(\mathrm{~m}^{3}\right)$.

$P_{(t)}=$ precipitação da chuva no tempo $t(\mathrm{~mm})$.

$V=$ volume do reservatório $\left(\mathrm{m}^{3}\right)$.

$C=$ coeficiente de escoamento superficial.

$\mathrm{A}=$ área de captação $\left(\mathrm{m}^{2}\right)$.

Por outro lado, o sistema hidrossanitário de aproveitamento da água cinza na edificação foi pensado de forma a efetuar a coleta das águas residuárias e separar a água cinza. Uma vez que se pode utilizar o mesmo reservatório para armazenar a água de chuva e o efluente tratado da água cinza, para seu dimensionamento, é necessário determinar a quantidade de água cinza gerada pelos moradores do edifício e adequar um reservatório que atenda às duas fontes.

Para estimar a quantidade de água cinza de forma precisa, próxima da realidade, alguns parâmetros presentes na bibliografia são propostos por diversos autores. Neste caso, levaram-se em conta dois critérios, conforme Tabelas 4 e 5.

Tabela 4 - Geração de água cinza com base nos parâmetros propostos por Melo e Azevedo Netto (1988).

\begin{tabular}{|l|c|c|}
\hline \multirow{2}{*}{\multicolumn{1}{|c|}{ Uso }} & \multicolumn{2}{c|}{ Quantidade de consumo (L/dia) } \\
\cline { 2 - 3 } & Proposto & Adotado \\
\hline Asseio pessoal & 30 a 60 & 45 \\
\hline Bebida & 2 & 0 \\
\hline Lavagem de roupas & 10 a 20 & 15 \\
\hline
\end{tabular}

Tabela 5 - Geração de água cinza com base nos parâmetros propostos por Gonçalves e Bazzarella (2005).

\begin{tabular}{|c|c|c|}
\hline Uso & Consumo per capita & $\begin{array}{c}\text { Consumo por } \\
\text { aparelho }\end{array}$ \\
\hline Lavatório & $3 \mathrm{~min} / \mathrm{dia}$ & $10 \mathrm{~L} / \mathrm{min}$ \\
\hline Chuveiro & $10 \mathrm{~min} / \mathrm{dia}$ & $12 \mathrm{~L} / \mathrm{min}$ \\
\hline Tanque & $5 \mathrm{~min} / \mathrm{dia}$ & $10 \mathrm{~L} / \mathrm{min}$ \\
\hline Máq. de lavar roupas & 3 ciclos/semana & $210 \mathrm{~L} / \mathrm{ciclo}$ \\
\hline
\end{tabular}

Fonte: Gonçalves e Bazzarella (2005)

\section{Dimensionamento da ETAC}

Para a ETAC, foi adotado o sistema proposto por Gonçalves (2006), em estudo do Programa de Pesquisas em Saneamento Básico (PROSAB), que desenvolveu uma estação desse tipo para uma edificação. 0 mesmo tratamento foi proposto por Bazzarella (2005), sendo capaz de tratar uma quantidade de água cinza produzida por 60 pessoas (24 L/hab.dia).

O funcionamento da ETAC é resumido da seguinte forma: a água bruta que vem da rede de coleta passa pelo tanque de equalização; após peneiramento, passa por um Reator Anaeróbio Compartimentado (RAC), em três tanques (RAC1, RAC2, RAC3), seguindo para o Filtro Biológico Aerado Submerso (FBAS) e, posteriormente, o Decantador Secundário de Placas (DEC); por fim, passa por um filtro terciário de membrana com clorador de pastilha, sendo armazenada no tanque de água cinza tratada.

Assim, o RAC foi previsto para assegurar uma eficiência mínima de $60 \%$ na remoção da Demanda Bioquímica de Oxigênio (DBO), para uma temperatura média da água residuária de $20^{\circ} \mathrm{C}$. Foi definido um tempo de detenção hidráulica ( $(t)$ de dez horas e compartimentação de três câmaras. $O$ volume útil do RAC pode ser determinado pela Equação 2:

$\mathrm{V}_{\mathrm{RAC}}=\mathrm{K}_{2} \cdot \mathrm{Q}_{\text {méd }} \cdot \mathrm{t}$ 
Em que:

$\mathrm{V}_{\text {RAC }}=$ volume útil do $\operatorname{RAC}\left(\mathrm{m}^{3}\right)$.

$\mathrm{K}_{2}=$ coeficiente de pico de horário $\left(\mathrm{K}_{2}=3\right)$.

$\mathrm{Q}_{\text {méd }}=$ vazão média de água cinza $\left(\mathrm{m}^{3} / \mathrm{h}\right)$.

$\mathrm{t}=$ tempo de detenção hidráulica (h).

O polimento do efluente do RAC é realizado pelo FBAS e possui um material de meio suporte, em que as colônias de microrganismos, responsáveis pela degradação biológica, fixam-se. O FBAS dáse em fluxo normal ascendente e é dimensionado com seção retangular, tomando-se como parâmetro principal de dimensionamento a carga orgânica volumétrica sobre o meio granular (CvDBO).

Segundo Gonçalves (2006), o cálculo dessa carga é descrito pela Equação 3, o volume do meio granular é obtido por meio da Equação 4 e a vazão de ar necessária para o funcionamento do biofiltro dá-se pela Equação 5.

$\mathrm{CDBO}_{\mathrm{FBAS}}=\left(1-\mathrm{E}_{\mathrm{RAC}}\right) \cdot \mathrm{K}_{2} \cdot \mathrm{Q}_{\text {méd }} \cdot \mathrm{DBO}$

$\mathrm{V}_{\mathrm{FBAS}}=\mathrm{CDBO}_{\mathrm{FBAS}} \div \mathrm{CVDBO}_{\mathrm{FBAS}}$

$\mathrm{Q}_{\mathrm{ar}}=\mathrm{T}_{\mathrm{ar}} \cdot \mathrm{CDBO}_{\mathrm{FBAS}}$

Em que:

$\mathrm{CvDBO}=0,5 \mathrm{kgDBO} / \mathrm{m}^{3} \cdot$ dia.

$\mathrm{DBO}_{5}=100 \mathrm{mg} / \mathrm{L}$ (valor médio de $\mathrm{DBO}_{5}$ da água cinza).

$\mathrm{h}_{\text {leito }}=1,50$ (altura útil do meio granular).
$E_{\mathrm{RAC}} \mathrm{DBO}_{5}=60 \%$ (eficiência de remoção de $\mathrm{DBO}_{5}$ do RAC).

$\mathrm{T}_{\mathrm{ar}}=30 \mathrm{Nm}^{3} / \mathrm{kgDBO}_{5}$ aplicado (taxa de aplicação de ar).

O decantador secundário foi dimensionado com seção retangular, prevendo uma taxa superficial $\left(t_{s}\right)$ de $25 \mathrm{~m}^{3} / \mathrm{m}^{2}$.dia, calculando a área superficial $\left(\mathrm{A}_{\mathrm{DEC}}\right)$ pela Equação 6:

$A_{D E C}=K_{2} \cdot Q_{\text {méd }} \div t_{s}$

Para o dimensionamento do filtro terciário, de geometria retangular, tomou-se como parâmetro principal de dimensionamento a velocidade ascensional ( $v$ ) de 4,0 m/h. 0 cálculo da área superficial é apresentado na Equação 7:

$A_{\mathrm{FT}}=K_{2} \cdot Q_{\text {méd }} \div v$

\section{Determinação das instalações hidráulicas}

Como esta pesquisa tinha como objetivo a avaliação da viabilidade técnica de um projeto de aproveitamento de águas pluvial e cinza, as instalações hidráulicas prediais do edifício em análise deviam ser diferentes das usuais. Assim, algumas diretrizes foram tomadas para a elaboração de um projeto sólido, que não apresentasse falhas, como a inadequada mistura de água potável com água reaproveitada. Nesse âmbito, o traçado das instalações prediais expõe-se como indispensável, identificando as tubulações referentes à captação da água cinza, à captação da água de chuva e à água potável. 


\subsection{Viabilidade econômica}

A viabilidade econômica deste projeto começa pela redução do consumo de água potável, fornecida pela concessionária local, a Companhia Riograndense de Saneamento (CORSAN). Quando uma edificação começa a utilizar a água de chuva e a água cinza, a qual seria descartada, abre-se mão de utilizar água potável, desonerando, assim, a conta desse recurso.

Com o volume de água não potável que será reaproveitado no prédio e o preço do metro cúbico de água de $\mathrm{R} \$ 4,09 / \mathrm{m}^{3}$, fornecido pela CORSAN (juIho/2014), foi possível fazer o cálculo de quanto será poupado, por meio da Equação 8:

$\mathrm{P}=\mathrm{V} \times \mathrm{T}$

Em que:

$\mathrm{P}=$ valor poupado com a utilização do projeto $(\mathrm{R} \$ /$ ano).

$\mathrm{V}=$ volume de água não potável reutilizado no edifício ( $\left.\mathrm{m}^{3} / \mathrm{ano}\right)$.

$\mathrm{T}$ = tarifa por $\mathrm{m}^{3}$ de água potável fornecido pela concessionária $\left(\mathrm{R} \$ / \mathrm{m}^{3}\right)$.

VPL

O VPL, também conhecido como método do valor atual, é um método matemático-financeiro capaz de determinar o valor presente de pagamentos futuros, descontando uma taxa de juros apropriada. Agostini (2009) propôs um método para o cálculo do VPL de um sistema (Equação 9), como o proposto neste trabalho, englobando também a economia gerada pelo sistema e os custos despendidos com ele.

$$
V P L=\left[\sum_{j=1}^{n} \frac{E \cdot\left(1+i_{A}\right)^{j}-C \cdot\left(1+i_{E}\right)^{j}}{(1+i)^{j}}\right]-I N V
$$

Em que:

$\mathrm{VPL}=$ valor presente líquido $(\mathrm{R} \$)$.

$\mathrm{j}$ = período temporal de avaliação (anual).

$\mathrm{n}$ = número de períodos considerados (vida útil).

$E=$ economia gerada pelos sistemas $(R \$)$.

$\mathrm{C}=$ custos relacionados com operação e manutenção dos sistemas (R\$).

$I N V=$ custo do investimento inicial dos sistemas (R\$).

$i=$ taxa de juros considerada.

$i A=$ taxa de aumento da tarifa de água potável da concessionária (anual).

$i E$ = taxa de aumento da tarifa de energia elétrica da concessionária (anual).

Para a aplicação da Equação 9, Pozzebon (2013) calculou a variação média de cada uma das taxas no período de 2000 a 2010, encontrando uma taxa de aumento da tarifa de energia elétrica $i E=$ 9,53 e de aumento da tarifa da água potável $i A=$ 7,52. Já a taxa de juros considerada foi a Taxa de Juros de Longo Prazo (TJLP) do Banco Nacional de Desenvolvimento Econômico e Social (BNDES), que tem vigência trimestral e, em todos os trimestres de 2013, ficou em 5\% ao ano (BNDES, 2013).

\section{RESULTADOS E DISCUSSÃO}

\subsection{Viabilidade técnica do aproveitamento da água de chuva}

Para o aproveitamento da água de chuva, foi utilizada uma série de dados históricos de precipitação de 20 anos (1990 a 2010), considerando uma área de 
captação de 418,75 m². Já a demanda de água não potável, para o abastecimento das bacias sanitárias, com a limpeza do condomínio, a rega dos jardins e a lavagem de carros, foi de $8,85 \mathrm{~m}^{3} / \mathrm{dia}$.

Por meio do método da simulação, o volume do reservatório escolhido foi de $15 \mathrm{~m}^{3}$, pois, pela curva de garantia (Figura 4), ficou evidente que, ao aumentar consideravelmente esse volume, o ganho com relação ao abastecimento era irrisório. $A$ garantia de abastecimento, ou seja, a quantidade de água poupada com a utilização de água pluvial, para um reservatório de $15 \mathrm{~m}^{3}$ é de aproximadamente $9,30 \%$ da demanda.

Como forma de comparação, Fasola et al. (2011) encontraram um potencial de economia de água potável para duas escolas em Santa Catarina. Tratandose de água cinza, foi de $4 \%$ a $5 \%$ de aproveitamento, enquanto o aproveitamento de água pluvial foi, em média, de $32,7 \%$. Há de se ressaltar o maior uso de água não potável nas escolas e, também, uma área de captação muito maior (638 e $800 \mathrm{~m}^{2}$ ), resultando em maior volume pluvial captado.

\subsection{Viabilidade técnica do aproveitamento de água cinza}

Um conjunto de parâmetros utilizados foi proposto por Melo e Azevedo Netto (1988), para consumo de água para usos residenciais, retratado na Tabela 6. Adotando valores intermediários para o consumo de água potável, chegou-se à geração de água cinza de 11,70 m²/dia, para cada uso dentro de uma residência. Para ter outros subsídios, foram utilizados os parâmetros propostos por Gonçalves e Bazzarella (2005), que resultaram numa geração de água cinza de $56,55 \mathrm{~m}^{3} /$ dia.

Tabela 6 - Geração de água cinza pelos parâmetros propostos por Melo e Azevedo Netto (1988).

\begin{tabular}{|c|c|c|c|c|}
\hline \multirow[t]{2}{*}{ Uso } & \multirow[t]{2}{*}{$\begin{array}{c}\mathrm{N}^{\circ} \mathrm{de} \\
\text { pessoas }\end{array}$} & \multicolumn{2}{|c|}{$\begin{array}{l}\text { Quantidade de } \\
\text { consumo (L/dia. } \\
\text { pessoa) }\end{array}$} & \multirow{2}{*}{$\begin{array}{c}\text { Geração de } \\
\text { água cinza } \\
\text { (m²/dia) }\end{array}$} \\
\hline & & Proposto & Adotado & \\
\hline Asseio Pessoal & \multirow{3}{*}{195} & 30 a 60 & 45 & 8,75 \\
\hline Bebida & & 2 & 0 & 0,00 \\
\hline $\begin{array}{l}\text { Lavagem de } \\
\text { Roupas }\end{array}$ & & 10 a 20 & 15 & 2,93 \\
\hline \multicolumn{4}{|l|}{ Total } & 11,70 \\
\hline
\end{tabular}

Fonte: Adaptado de Melo e Azevedo Netto (1988).

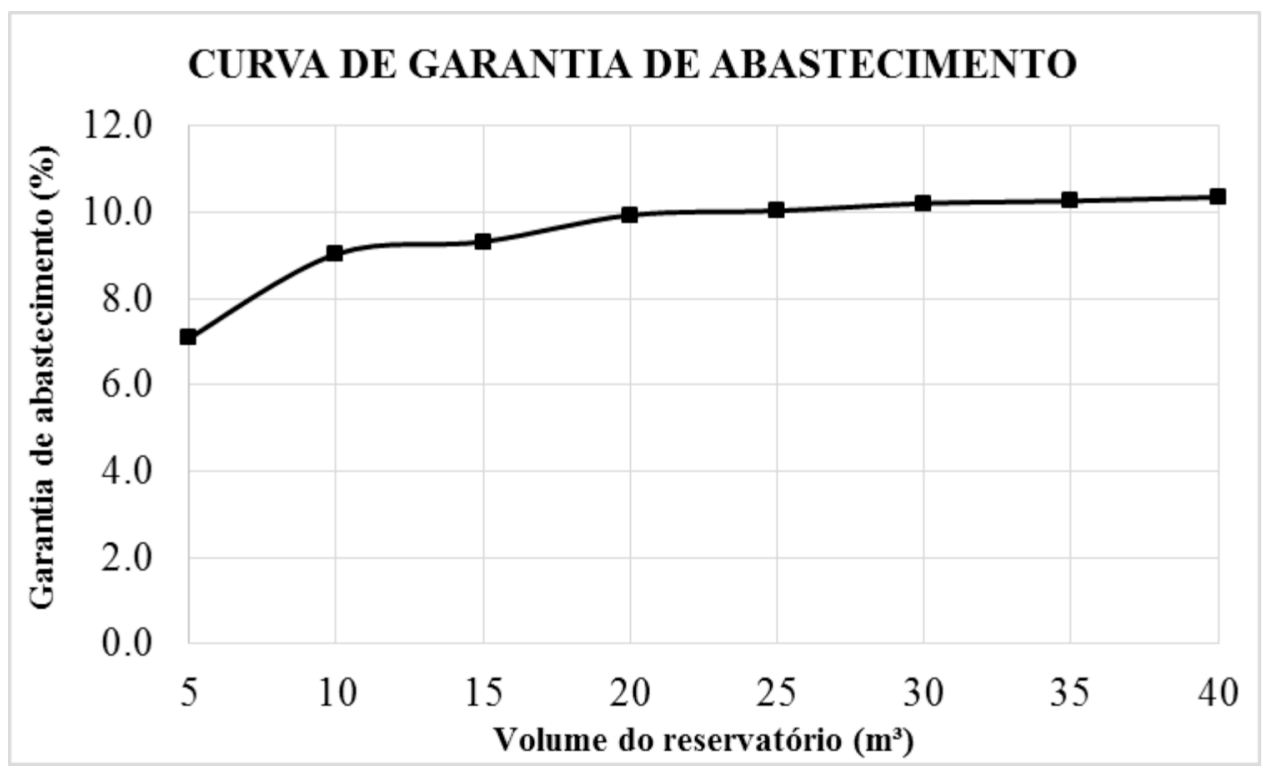

Figura 4 - Curva de garantia de abastecimento. 
Tendo ocorrido uma diferença grande entre os valores obtidos nas duas simulações, optou-se pela quantia de água cinza gerada pelos parâmetros de Melo e Azevedo Netto (1988), considerando a segurança.

Como a oferta pluviométrica na região é incapaz de abastecer a demanda estimada para o Residencial Gabro, o reservatório de $15 \mathrm{~m}^{3}$ seria capaz de atender a cerca de 7,20\% da demanda. Uma alternativa seria a mistura da água cinza tratada com a água de chuva. Assim, em períodos de estiagem, a produção de água cinza poderia suprir a falta da água de chuva.

Diferentemente do caso tratado neste trabalho, comparando com os resultados obtidos por Fasola et al. (2011), o aproveitamento de água cinza mostrou-se uma estratégia inviável, pois não existiam aparelhos que ofertassem grande volume de efluentes, como chuveiros ou máquinas de lavar roupas. Por outro lado, Jamrah et al. (2007) investigaram o potencial de aproveitamento de água cinza em cinco residências na cidade de Oman e encontraram uma fração de geração de água cinza em torno de $83 \%$ do total de água consumida, mostrando uma grande capacidade de geração em edificações residenciais.

\section{Dimensionamento da ETAC}

A ETAC do edifício ficou localizada no subsolo; como o pé-direito tinha $2,65 \mathrm{~m}$, foi arbitrada uma altura de 2,00 m para ela. Para a produção diária de $11,70 \mathrm{~m}^{3}$ de água cinza, tinha-se, então, uma vazão de $0,488 \mathrm{~m}^{3} / \mathrm{h}$.

A área total do RAC era de 10,20 $\mathrm{m}^{2}$ e a área de cada câmara, 3,40 $\mathrm{m}^{2}$. Então, cada câmara tinha dimensões de $1,20 \times 2,90 \times 2,00 \mathrm{~m}$, tendo o RAC completo $3,60 \times 2,90 \times 2,00 \mathrm{~m}$.
Para o biofiltro, as dimensões adotadas foram: 1,20 $\times 1,60 \times 2,00 \mathrm{~m}$, com altura do leito de 1,50 m. As dimensões adotadas para o DEC foram: $1,20 \times 1,25 \times$ 2,00 m e para o filtro terciário: $0,60 \times 0,65 \times 2,00 \mathrm{~m}$.

A desinfecção com cloro é feita no reservatório de água, em que ocorre a mistura da água cinza tratada com a água de chuva. O cloro é capaz de remover a cor remanescente dos tratamentos anteriores, garantir a completa desodorização e prevenir a proliferação de bactérias no reservatório (BAZARELLA, 2005). Assim, com uma concentração de $3 \mathrm{mg} / \mathrm{L}$, serão gastos anualmente $14,4 \mathrm{~kg}$ de cloro para o tratamento das águas residuárias.

A representação esquemática do sistema proposto para o aproveitamento de água, com o sistema de aproveitamento de água cinza e a ETAC, é mostrada na Figura 5.

\subsection{Viabilidade econômica do sistema}

De acordo com a atual estrutura tarifária da CORSAN, o Residencial Gabro enquadra-se na categoria Básica Residencial B. Assim, a conta de consumo de água é formada pelo preço do serviço básico (R\$ 19,35) e pela quantidade de água utilizada, que é multiplicada pelo preço-base $\left(\mathrm{R} \$ 4,09 / \mathrm{m}^{3}\right)$.

Como o serviço básico seria cobrado com ou sem o aproveitamento de água de chuva, ele não foi considerado no cálculo da economia gerada pela utilização do sistema. Portanto, chegou-se a um volume de 10,28 $\mathrm{m}^{3}$ de água potável poupada por dia, resultando numa economia anual de $\mathrm{R} \$ 15.346,50$.

O resumo da relação de materiais, mão de obra e custos de implantação do sistema de aproveitamento da água de chuva e tratamento/ aproveitamento de água cinza é mostrado na Tabela 7. Os valores foram consultados na tabela do Sistema Nacional de Pesquisa de Custos e Índices da Construção Civil (SINAPI), pu- 


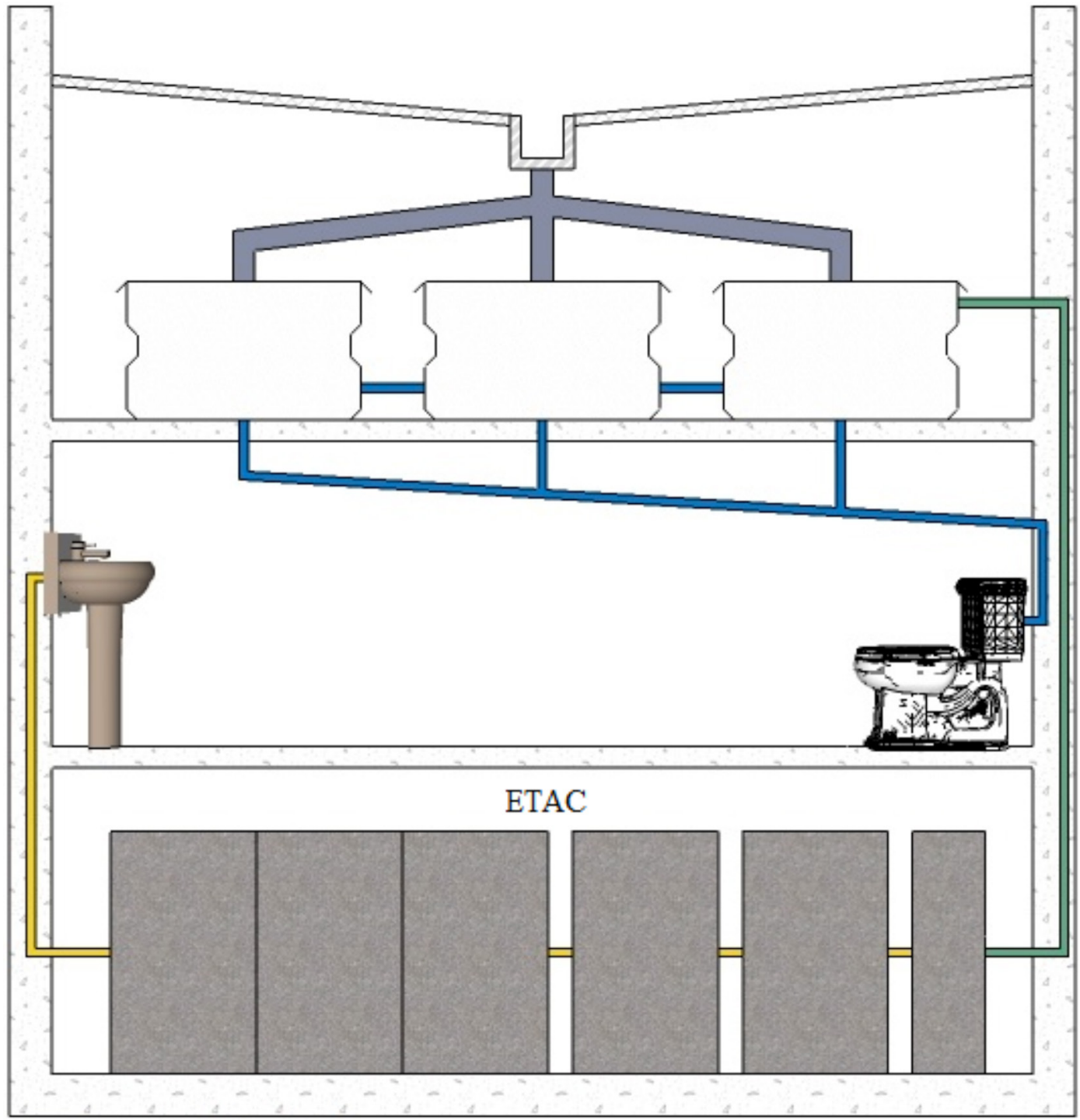

Captação da água da chuva

Tubulação de recalque de água cinza tratada

Rede de coleta de água cinza

Rede de distribuição

Figura 5 - Esquema do sistema avaliado.

blicada em novembro de 2013, e a mão de obra foi estimada em $35 \%$ do valor do material.

De forma explicativa, alguns dos materiais utilizados para a implantação do sistema foram: tubulações e conexões de policloreto de polivinila (PVC), dispositivo de descarte, filtro industrial, freio d'água, sifão ladrão, sistema realimentador automático, material elétrico, registro de gaveta, dosador de cloro, rede de coleta, tanque de equalização, sistema de tratamento da água cinza, tanque de água cinza tratada e sistema de recalque. 
Tabela 7 - Resumo da planilha de custos de implantação, manutenção e mão de obra.

\begin{tabular}{|c|l|c|c|c|}
\hline Item & \multicolumn{1}{|c|}{ Descrição } & Mat. (R\$) & $\begin{array}{c}\text { Mão de } \\
\text { obra (R\$) }\end{array}$ & Total (R\$) \\
\hline 1 & $\begin{array}{l}\text { Sistema de coleta e } \\
\text { dist. da água pluvial }\end{array}$ & $14.572,83$ & $5.100,49$ & $19.673,32$ \\
\hline 2 & $\begin{array}{l}\text { Rede de coleta de } \\
\text { água cinza }\end{array}$ & $5.180,49$ & $1.813,17$ & $6.993,66$ \\
\hline 3 & $\begin{array}{l}\text { Tanque de } \\
\text { equalização }\end{array}$ & $1.618,00$ & 566,30 & $2.184,30$ \\
\hline 4 & RAC & $2.133,08$ & 746,58 & $2.879,66$ \\
\hline 5 & FBAS & $2.181,74$ & 763,61 & $2.945,35$ \\
\hline 7 & $\begin{array}{l}\text { Decantador } \\
\text { secundário }\end{array}$ & $2.133,08$ & 746,58 & $2.879,66$ \\
\hline 8 & $\begin{array}{l}\text { Filtro terciário } \\
\text { cinque de água }\end{array}$ & $2.613,94$ & 914,88 & $3.528,82$ \\
\hline 9 & Sistema de recalque & $1.618,00$ & 566,30 & $2.184,30$ \\
\hline 10 & $\begin{array}{l}\text { Manutenção do } \\
\text { sistema }\end{array}$ & $2.296,93$ & 168,30 & $2.465,23$ \\
\hline Total & \multicolumn{2}{|l|}{} & & $48.139,77$ \\
\hline
\end{tabular}

As instalações hidrossanitárias do edifício já haviam sido projetadas e, portanto, inclusas no orçamento da obra. Assim, apenas novos materiais foram contabilizados no estudo da viabilidade econômica do aproveitamento da água de chuva.

Por fim, a Figura 6 mostra que o sistema é economicamente viável, pois o investimento inicial é recuperado logo no segundo ano de utilização. Ao final dos 20 anos de vida útil, o sistema acu- mula um valor de $\mathrm{R} \$ 272.615,83$, que não pode ser considerado lucro, pois não há retorno para os cofres do condomínio, por exemplo. Contudo, uma considerável quantia em dinheiro é poupada, justamente pela utilização do sistema.

\section{CONCLUSÕES}

O dimensionamento do sistema de aproveitamento de águas de chuva e cinza foi realizado para o edifício Residencial Gabro, cuja população foi estimada em 195 pessoas, consumindo 8,85 $\mathrm{m}^{3} /$ dia de água não potável para abastecer suas bacias sanitárias, fazer a limpeza do condomínio uma vez por semana e a rega das plantas.

Utilizando o método da simulação, foram dimensionados reservatórios para a área de captação de $418,75 \mathrm{~m}^{2}$, visando a uma maior eficiência de reservação de água pluvial. Assim, o reservatório de $15 \mathrm{~m}^{3}$ garante o abastecimento total de água não potável, em $100 \%$ do tempo de vida útil do sistema de aproveitamento de águas pluvial e cinza.

Da mesma forma, o aproveitamento da água cinza é viável tecnicamente, visto que há uma produção no edifício de $11,70 \mathrm{~m}^{3} / \mathrm{dia}$, que atende totalmente à demanda de água não potável da edificação. $O$ sis-

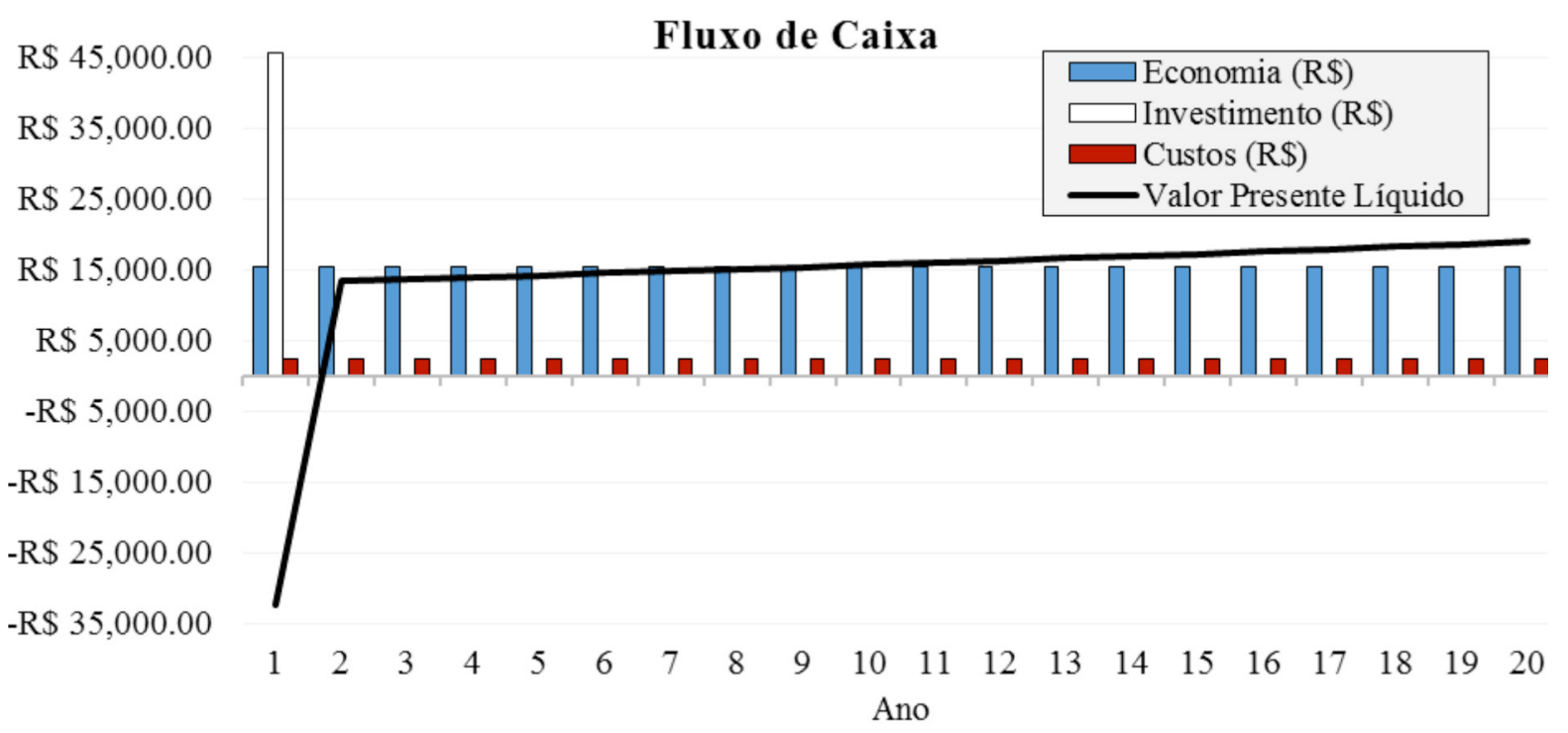

Figura 6 - Fluxo de caixa do sistema. 
tema de água de chuva misturado com água cinza poupa anualmente $3.752,20 \mathrm{~m}^{3}$ de água potável.

Do ponto de vista econômico, apesar do investimento inicial de $R \$ 45.674,54$, o sistema, além de ser viável, gera uma economia de água potável, que seria paga à concessionária, extremamente alta. Isso é explicado porque cerca de 30\% a 35\% da água que se utiliza é para fins não potáveis. Ao fazer um balanço dos custos de implantação e da economia gerada pelo sistema em 20 anos, chega-se a um valor de $\mathrm{R} \$ 272.615,83$, que seria poupado de ser pago à companhia que faz a distribuição da água no município.

Em suma, a utilização de um sistema como o abordado neste trabalho traz benefícios econômicos e ambientais. Além disso, pode acontecer sem problema algum, uma vez que foi mostrado que é tecnicamente viável.

\section{REFERÊNCIAS}

AGÊNCIA NACIONAL DAS ÁGUAS, FEDERAÇÃO DAS INDÚSTRIAS DO ESTADO DE SÃO PAULO e SINDICATO DA INDÚSTRIA DA CONSTRUÇÃOCIVIL DE SÃO PAULO. Conservação e Reuso de água em Edificações. São Paulo: Prol Editora Gráfica. 2005.

AGOSTINI, R. D. S. D. Avaliação do desempenho e da viabilidade econômica de um sistema de reuso de água cinza em um edifício residencial de alto padrão. Projeto de graduação; UFES. Vitória, 70 p.,2009.

AL-JAYYOUSI, Odeh R.. Greywater reuse: towards sustainable water management. Desalination, Amã, v. 1, n. 156, p.181-192, 1 ago. 2003.

ASSOCIAÇÃO BRASILEIRA DE NORMAS TÉCNICAS. NBR 10844: Instalações prediais de águas pluviais: procedimento. Rio de Janeiro, $1989.13 \mathrm{p}$.

ASSOCIAÇÃO BRASILEIRA DE NORMAS TÉCNICAS. NBR 12213: Projeto de captação de água de superfície para abastecimento público. Rio de Janeiro, 1992. 05 p.

ASSOCIAÇÃO BRASILEIRA DE NORMAS TÉCNICAS. NBR 12214: Projeto de sistema de bombeamento de água para abastecimento público. Rio de Janeiro, 1992. 15p.

ASSOCIAÇÃO BRASILEIRA DE NORMAS TÉCNICAS. NBR 12217: Projeto de reservatório de distribuição de água para abastecimento público. Rio de Janeiro, 1994. 4 p.
ASSOCIAÇÃO BRASILEIRA DE NORMAS TÉCNICAS. NBR 13969: Tanques sépticos - unidades de tratamento complementar e disposição final dos efluentes líquidos - projeto, construção e operação. Rio de Janeiro, 1997.60 p.

ASSOCIAÇÃO BRASILEIRA DE NORMAS TÉCNICAS. NBR 15097: Aparelhos sanitários de material cerâmico - Requisitos e métodos de ensaio. Rio de Janeiro, 2004. 37p.

ASSOCIAÇÃO BRASILEIRA DE NORMAS TÉCNICAS. NBR 15527: Água de chuva: aproveitamento de coberturas em áreas urbanas para fins não potáveis: requisitos. Rio de Janeiro, 2007. 8 p.

ASSOCIAÇÃO BRASILEIRA DE NORMAS TÉCNICAS. NBR 5626: Instalação predial de água fria. Rio de Janeiro, 1998. 41 p.

BAZZARELLA, Bianca Barcellos. Caracterização e aproveitamento de água cinza para uso não potável em edificações. $165 \mathrm{f}$. Dissertação (Mestrado) - Universidade Federal do Espirito Santo, Vitória, 2005.

BRASIL. Ministério da Saúde. Portaria nº 2914, de 12/2011. Diário Oficial da República Federativa do Brasil, Poder Executivo, Brasília, DF, 12 dez. 2011. Seção 1, p. 39-46.

BRASIL. Resolução CONAMA n 274, de 29 de novembro de 2000. Diário Oficial da República Federativa do Brasil, Poder Executivo, Brasília, DF, 08 janeiro de 2001.

BRASIL. Resolução CONAMA n 357, de 17 de março de 2005. Diário Oficial da República Federativa do Brasil, Poder Executivo, Brasília, DF, 18 março de 2005.

BNDES. Banco Nacional do Desenvolvimento Econômico e Social. Taxa de Juros de Longo Prazo - TJLP. 2013. Disponível em: http:// www.bndes.gov.br/SiteBNDES/bndes/bndes_pt/Ferramentas_e_ Normas/Custos_Financeiros/Taxa_de_Juros_de_Longo_Prazo_ TJLP/index.html>. Acesso em: 24 dez. 2013.

CÂMARA MUNICIPAL DE CURITIBA. Lei Municipal n. 10.785, de 18 de setembro de 2003. Cria no Município de Curitiba, o Programa de Conservação e Uso Racional da Água nas Edificações - PURAE. Disponível em: <http://www.cmc.pr.gov.br>. Acesso em: 13 out. 2013.

COMPANHIA DE SANEAMENTO BÁSICO DO ESTADO DE SÃO PAULO - SABESP. Norma Técnica Sabesp NTS 181. São Paulo, 2012. $26 \mathrm{p}$.

CURITIBA. Decreto n ${ }^{\circ}$ 293, de 22 de março de 2006. Regulamenta a Lei $n^{\circ} 10.785 / 03$ e dispõe sobre os critérios do uso e conservação racional da água nas edificações e dá outras providências. Curitiba, 2006.

ECORACIONAL. Como instalar. Disponível em: <http://loja.ecoracional.com.br/comoinstalar>. Acesso em: 07 abr. 2014.

FASOLA, Gabriel Balparda et al. Potencial de economia de água em duas escolas em Florianópolis, SC. Ambiente Construído, Porto Alegre, v. 11, n. 4, p.65-78, out./dez. 2011. 
FERNANDES, Diogo Robson Monte; MEDEIROS NETO, Vicente Batista de; MATTOS, Karen Maria da Costa. Viabilidade econômica do uso da água da chuva: um estudo de caso da implantação de cisterna na UFRN / RN. In: Encontro Nacional De Engenharia De Produção, 27. 2007, Anais. Foz do Iguaçu, 2007.

GONÇALVES, Ricardo Franci (Coordenador). Uso Racional da Água em Edificações. Rio de Janeiro: ABES, 2006.

GONÇALVES, R.F.; BAZZARELLA, B.B. Reuso de águas cinzas e gerenciamento alternativo das águas amarelas (urina) em áreas urbanas. Anais eletrônicos do Workshop sobre Reuso. Campina Grande, PB, 2005.

JAMRAH, Ahmad et al. Evaluating greywater reuse potential for sustainable water resources management in Oman. Environmental Monitoring And Assessment, Oman, v. 137, n. 2, p.315-327, 12 jun. 2007.

JEPPESEN, B.. Domestic greywater re-use: Australia's challange for the future. Desalination, Brisbane, v. 3, n. 106, p.311-315, jun. 1997.

KRAYCHETE, Gabriel. Como fazer um Estudo de Viabilidade Técnica/Econômica. In: Consulta Economia Popular: Viabilidade e Alternativas. Promovido pela CESE - CEDAe. Salvador, 1997.

LOURENÇO, Luana. Brasil pode enfrentar falta de água. Disponível em: <http://www.progresso.com.br/caderno-a/brasil-mundo/ brasil-pode-enfrentar-falta-de-agua>. Acesso em: 20 set. 2013.

LI, Fangyue; WICHMANN, Knut; OTTERPOHL, Ralf. Review of the technological approaches for grey water treatment and reuses. Science Of The Total Environment, Hamburgo, v. 11, n. 407, p.3439-3449, 15 maio 2009. Quinzenal.
MADUNGWE, Emaculate; SAKURIGWA, Saniso. Greywater reuse: A strategy for water demand management in Harare?. Physics And Chemistry Of The Earth, Dar Es Salaam, v. 32, n. 17, p.1231-1236, 3 ago. 2007.

MELO, V.O., AZEVEDO NETTO, J.M., Instalações Prediais Hidráulico-Sanitárias, Editora Edgard Blucher Ltda, São Paulo, 1988.

POZZEBON, P. H. B. Viabilidade técnica, econômica e social do aproveitamento das águas de chuva e cinzas para consumo não potável na cidade de Santa Maria/RS. 193 f. Dissertação (Mestrado) - UFSM, Santa Maria, 2013.

RUPP, Ricardo Forgiarini; MUNARIM, Ulisses; GHISI, Enedir. Comparação de métodos para dimensionamento de reservatórios de água pluvial. Ambiente Construído, Porto Alegre, v. 11, n. 4, p.4764, out./dez. 2011.

SALLA, Marcio Ricardo et al. Viabilidade técnica de implantação de sistema de aproveitamento de água pluvial para fins não potáveis em universidade. Ambiente Construído, Porto Alegre, v. 13, n. 2, p.167-181, abr./jun. 2013.

SAMPAIO, Anne Raquel. Reuso da Água. Revista Brasileira de Saneamento e Meio Ambiente: BIO, Rio de Janeiro, p.16-29, jun. 2006.

TOMAZ, P. Aproveitamento de água de chuva. São Paulo: Navegar Editora, 2003.

TOMAZ, Plínio. Aproveitamento de água de chuva de telhados em áreas urbanas para fins não potáveis: Diretrizes básicas para um projeto. In: Simpósio Brasileiro De Captação Da Água De Chuva, Belo Horizonte, MG. 2007. 